\title{
Studying the Earth from Space
}

$\operatorname{lill}^{2}$
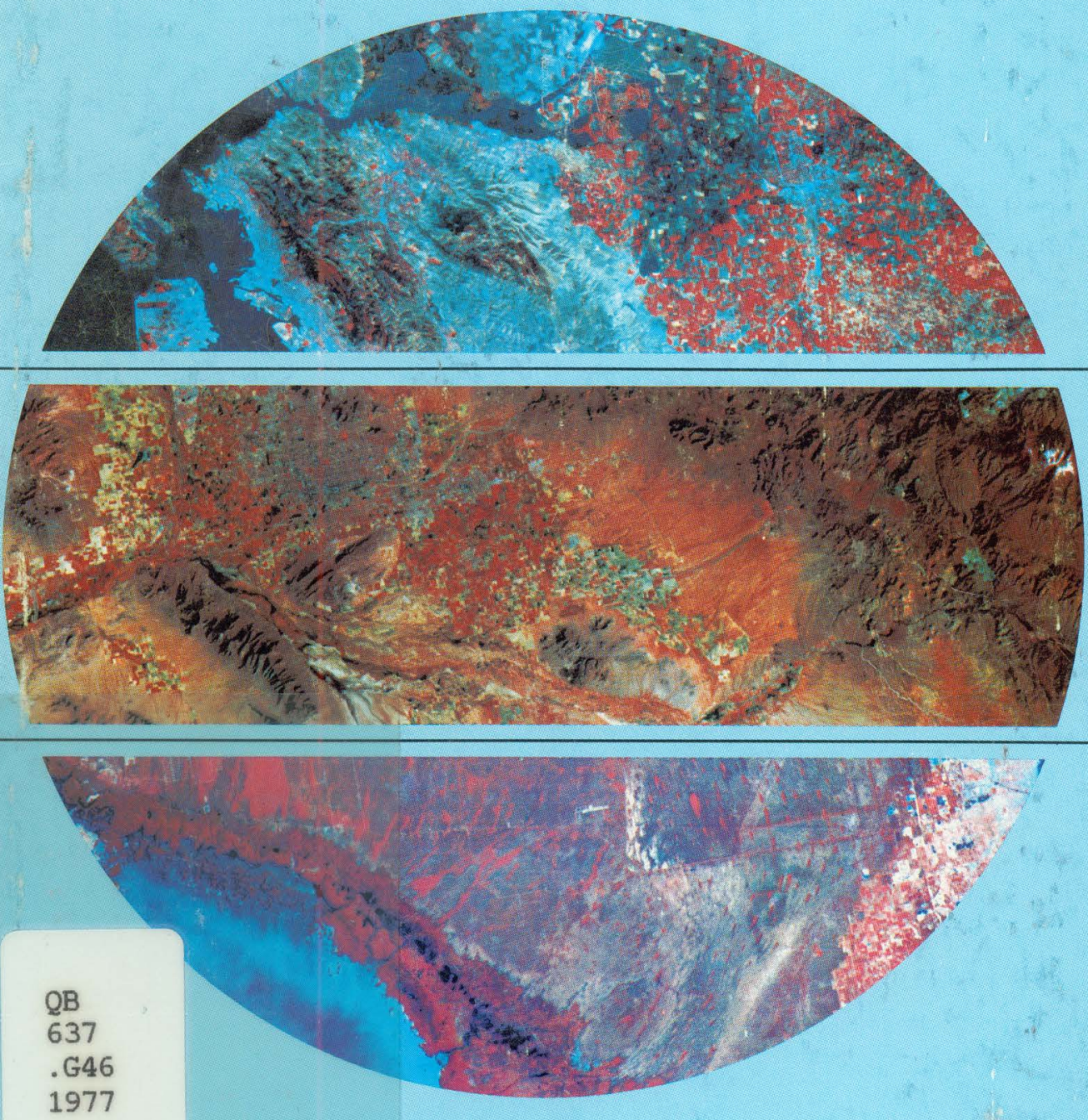

1977

U.S. Department of the Interior/Geological Survey 
The

Tools
Procerty of:

Don Kulow Library

EROS Data Center

Sioux Falls, SD 57198

Space age technology contains a key to increased knowledge about the Earth's resources; this key is remote sensing-detecting the nafure or condition of something without actually touching it. An early and still most useful form of remote sensing is photography which records the scene, as man sees it, on film sensitive to that part of the electromagnetic spectrum called visible energy. Electromagnetic energy travels in waves of various lengths; most are invisible to the human eye. Wavelengths progressively longer than those that the eye can see are infrared and microwave. Wavelengths progressively shorter than the eye can see are ultraviolet, $\mathrm{X}$-rays, and gamma rays.

Instruments can produce photographs and images (pictures other than those produced by photographic cameras) of energy distribution in each part of the electromagnetic spectrum. These instruments include photographic cameras, scanning radiometers, and radar. Each part of the electromagnetic spectrum is particularly suitable for providing information about some aspect of the world.

Black-and-white aerial photography, used stereoscopically, can provide accurate measurements of the size, shape, and location of objects. It is routinely used to prepare topographic maps, to survey agricultural crops and timber stands, to assess storm damage, to select sites for engineering works, and to map structural geologic features such as faults and folds.

Color increases the usefulness of photography for differentiating rocks and soils, vegetation, surface-water area and turbidity, and materials in houses, roads, and other objects on the Earth's surface. 
Color infrared photography, developed for detection of camouflaged installations during World War II, records some information that man cannot see but that can be recorded on film, increasing recognition of vegetation and its condition. Leaves of healthy plants generally have a high reflectance in the infrared region of the electromagnetic spectrum and by convention, are recorded as red for contrast with unhealthy or dead vegetation which appears green or blue. Variations in red tone may indicate the presence of more than one species or the presence of unhealthy plants, because the amount of infrared reflectance varies with leaf structure and plant vigor. Infrared photography also provides clues to the availability of water and to the physical character and mineral constituents of soils, because these factors significantly affect the distribution and vigor of vegetation.

Special detectors permit images to be produced from parts of the spectrum that are invisible to photographic film. These detectors convert electromagnetic energy to electrical energy that either activates a light source such as a cathode-ray tube (similar to a TV-picture tube) to produce an image or activates an electronic device that records directly on magnetic tape (similar to a tape recorder). Some of the instruments (radiometers) measure energy emitted in the infrared wavelengths from an object and, in fact, record radiant temperatures at or near the Earth's surface. Other instruments measure reflected and emitted energy in the microwave and longer wavelengths. Some radiometers and radars produce an image by scanning a scene line by line and are therefore called scanners. Some

Diseased or stressed vegetation appears light-colored or bluish in infrared photographs, such as this one of an area of Southern pine in Copiah County, Mississippi, taken February 2, 1973 Healthy vegetation appears red or pinkish.

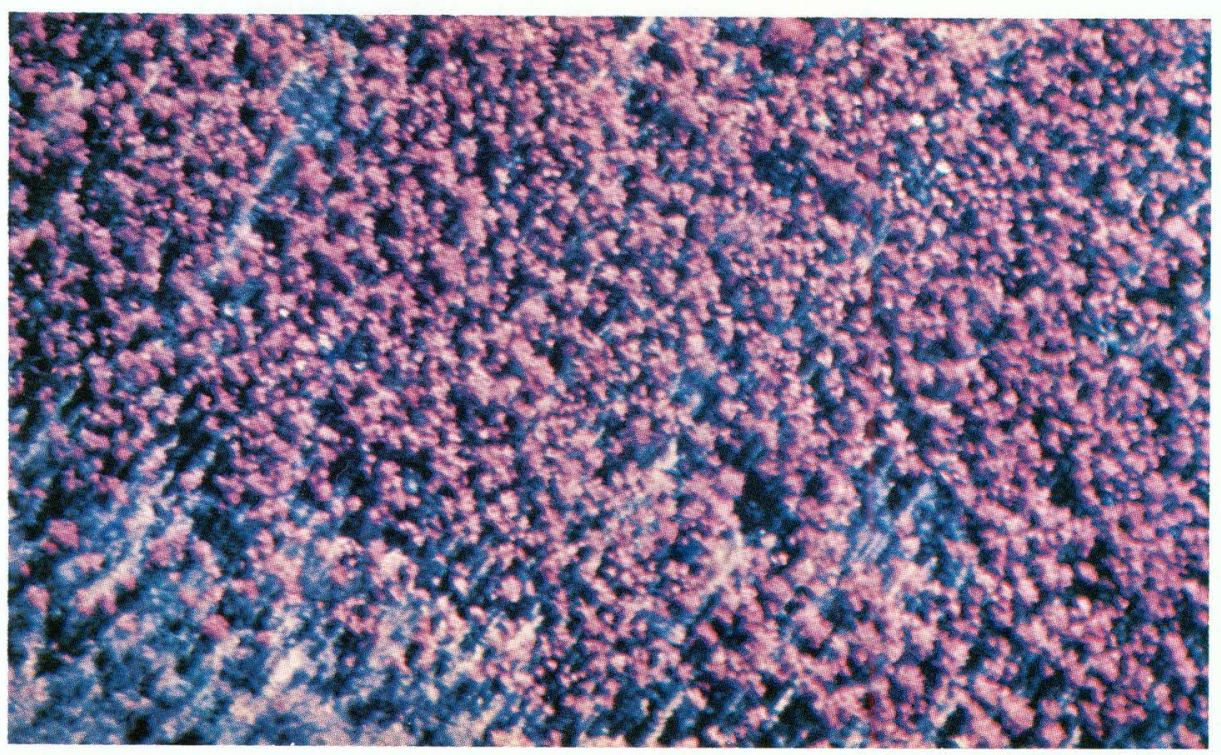

instruments may be used during the day or at night, and many radar systems can observe the surface of the Earth through clouds.

Infrared sensing instruments can remotely measure surface temperatures and map their distribution. They can reveal thermal areas, volcanic activity, fires normally obscured by smoke, underground fires, heated buildings, and wild animals. Such observations can, by revealing surface temperature distributions in water, aid in the discovery of springs discharging into lakes, rivers, and oceans and provide information on moisture conditions near the ground surface. These observations can also indicate, indirectly, physical properties of soils and rocks because retention or loss of heat are primarily determined by these characteristics.

Radar records the reflection of radio signals transmitted from aircraft or spacecraft to the ground. The signals are affected by the roughness and slope of the reflecting surfaces and the electrical properties of materials. Radar has been particularly useful in revealing geologic structures, studying ice distribution and characteristics, and mapping terrain obscured by clouds. There are many other types of remote-sensing instruments, but these are the more common ones.

The proper selection of sensors must be based on what is to be detected and what its spectral response will be compared with that of its surroundings. Optimum selection continues to be the subject of long and difficult investigations. Almost invariably, however, a combination

One tool for developing synoptic terrain maps is airborne, side-looking radar which defines valleys, slopes, ridges, and other topographic features. This radar image of a portion of the San Francisco peninsula shows the San Andreas fault zone and related faults. Note how water surfaces reflect radar waves away from the receiver and appear black. Near-surface moisture in soils generally appears dark gray.

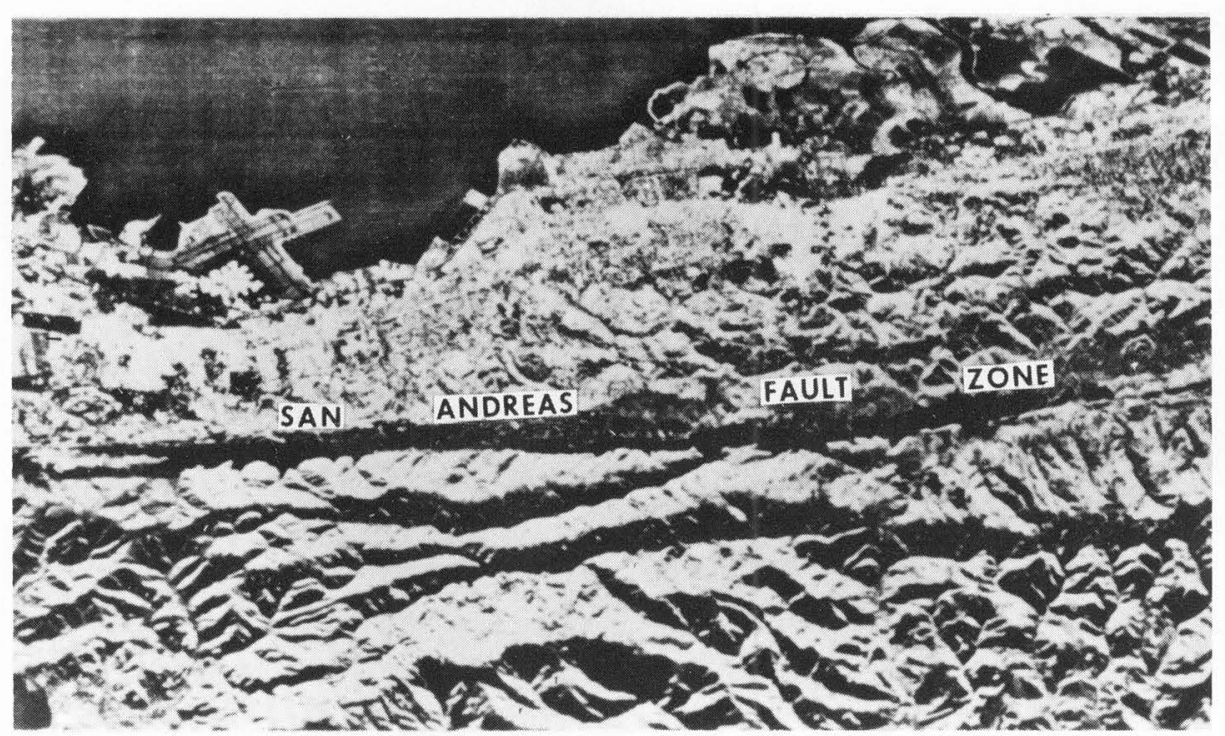


of spectral observations increases the information; that is, two distinct spectral observations provide more than twice as much information as one distinct observation. Experiments show that the best results are obtained by using more than one picture of the same scene, with each picture recording a different wavelength band within the visible and infrared parts of the spectrum. This system is called multispectral photography or imagery and is used on both aircraft and satellites.

These images were reconstructed from the Multispectral Scanner (MSS) aboard Landsat-1, and were made simultaneously on October 10, 1972

Area shown includes New Orleans, Louisiana (left of center), the Mississippi River, Lake Pontchartrain, Mouth of the Mississippi River (lower right), and the Mississippi Gulf Coast.
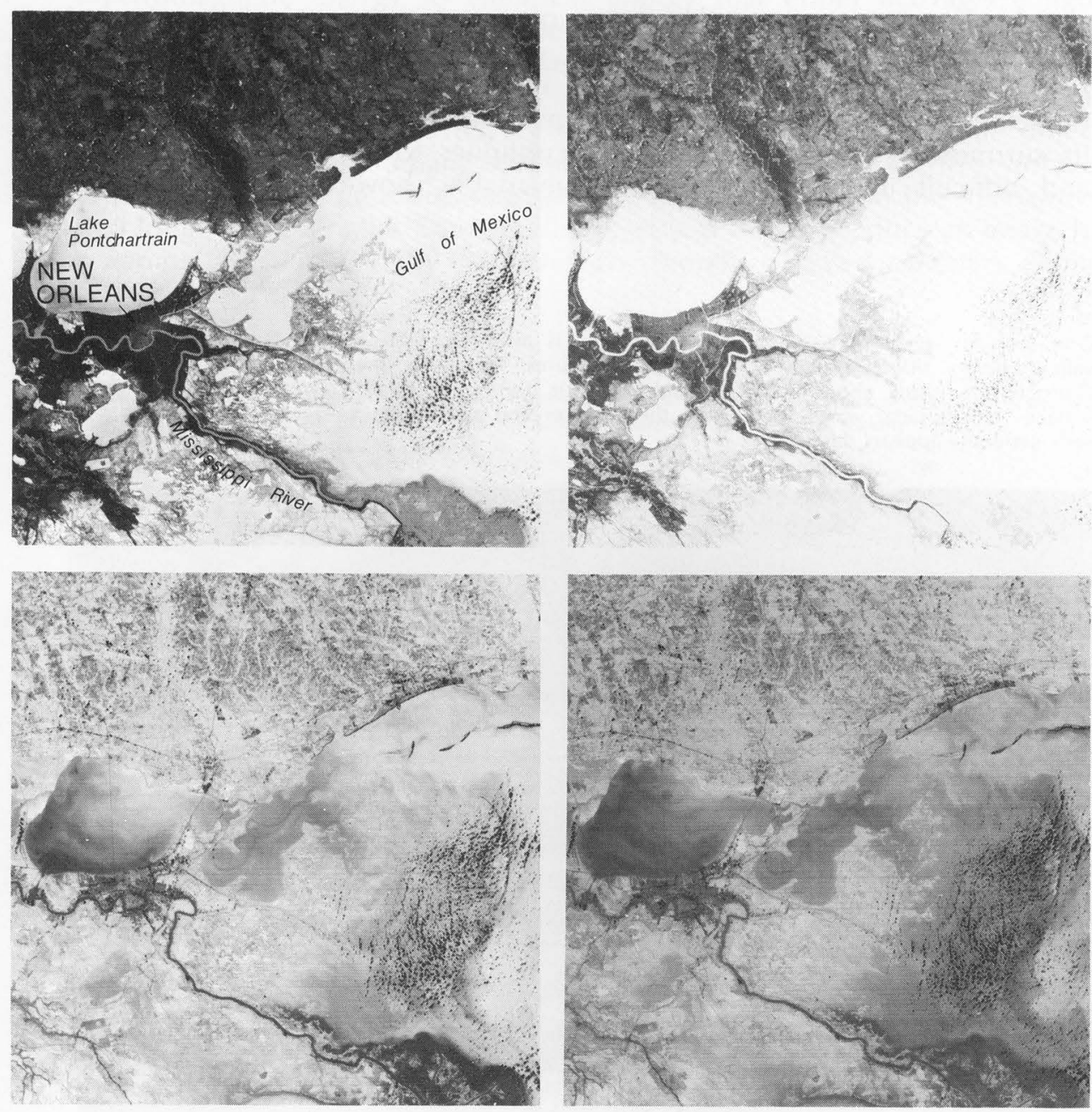

\section{Interpretation \\ of Space Data}

The first significant test of acquiring Earth-resources data by remote sensing from space was made during the Apollo 9 flight in March 1969. Multispectral photographs were obtained of the southern part of the United States using a cluster of four Hasselblad $70-\mathrm{mm}$ cameras. This experiment demonstrated the usefulness of the multispectral approach that was later employed on the first experimental Landsat satellite (formerly ERTS-1) launched July 23, 1972, and Landsat-2 launched January 22, 1975, both from Vandenburg Air Force Base, California.

Each Landsat experimental satellite is in a circular, near-polar, sunsynchronous orbit so that the same point on the Earth's surface is viewed every 18 days at the same time of day. The orbit is at an altitude of about 920 kilometers (about $570 \mathrm{mi}$ ). Each satellite carries a multispectral scanner, providing data in four wavelength bands, and vidicon (TV-type)

The terrain on the northwest coast of Australia is presented in this image of the Collier Bay area. The desert environment accentuates the structurally complex Wyndam Range at the bottom of the image. The coastal mangrove fringe appears red with salt-encrusted areas on the mainland white. The shallow roastal sea floor and coralline reefs, such as around Montgomery Island, appear in various shades of blue, the lightest shades are the shallowest. Information from images such as this can be used to improve existing bathymetric charts. Landsat image 1020-01143,

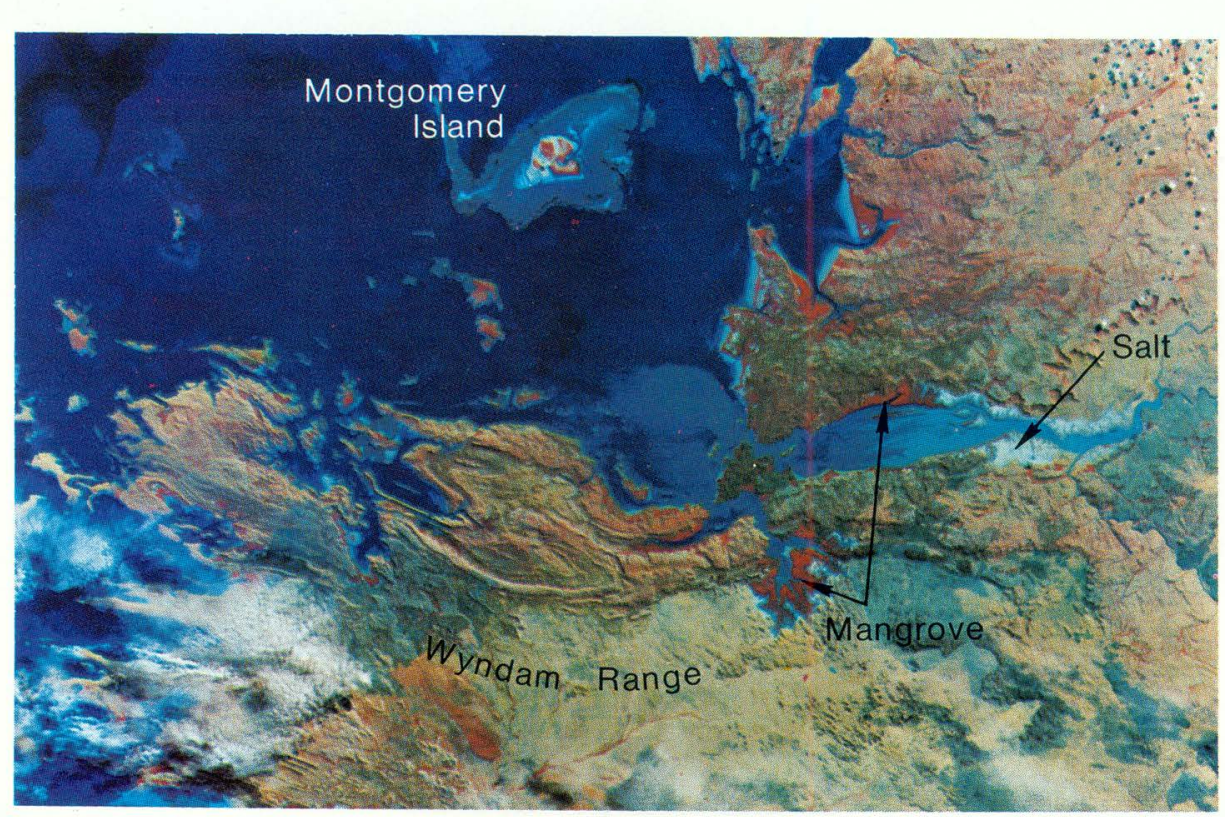


cameras operating in three wavelength bands; both types of instruments record in the visible and near-infrared parts of the electromagnetic spectrum. The original information is returned to Earth as electronic signals, recorded on magnetic tape suitable for computer analysis, and then converted to photographic-type images. The satellites also have radio relay systems to collect and transmit data from ground sensors, such as stream gages, seismic event counters, volcano tiltmeters, and meteorological instruments.

The Apollo experiment also contributed to the development of the Earth Resources Experiment Package (EREP) carried aboard Skylab when it was launched in May 1973. Skylab, a manned satellite, returned Earth resources data on film and magnetic tape. The EREP on board Skylab consisted of a multispectral scanner providing data in 13 wavelength bands; a multispectral camera providing photographs in 6 wavelength bands; an Earth Terrain Camera with a 457-mm (18-in) focal length lens that obtained photographs in black and white and in color; an infrared spectrometer that recorded on magnetic tape data in the visible through infrared wavelengths; a microwave radiometer/scatterometer and altimeter : and an L-band microwave radiometer. Skylab orbited the Earth at an altitude of about 426 kilometers (about $264 \mathrm{mi}$ ) and was occupied for three different

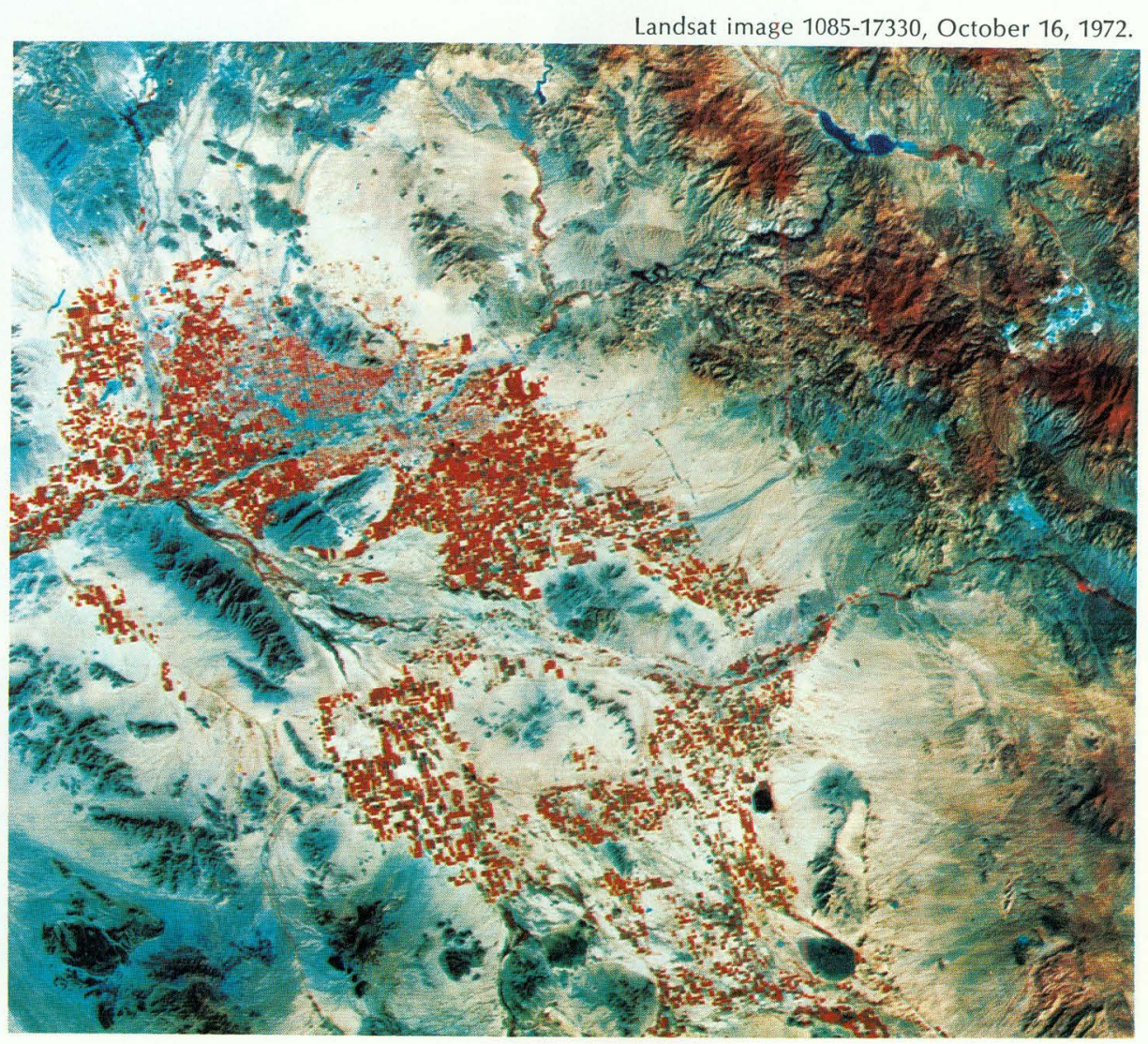

periods from May 1973 to February 1974. The remote sensors on these spacecraft were designed to meet the specifications of the Departments of the Interior and Agriculture. These Departments and many other investigators around the world are testing the data's application to planning, management, and conservation of resources. The investigations have shown that space data can be useful in such fields as cartography, geology, geography, hydrology, marine resources, agriculture, forestry, and land management. Many of these studies are concerned with mapping major geologic structures as they relate to mineral and fuel deposits, assessing hydrologic problems, determining the condition of rangeland, mapping changes in land use, studying erosion and change along coastlines and major streams, selecting better sites for large engineering works, and monitoring the environment.

Comparison of an October 16, 1972, Landsat image in false color of the Phoenix, Arizona area, with one taken on February 19, 1973, shows some of the many purposes served by repetitive space imagery. The reddish blush of the February image is caused primarily by the appearance of ephemeral range grasses responding to winter rains. The increased moisture is also reflected in the size of the reservoirs, especially Theodore Roosevelt Reservoir in the upper right. Mining can be identified and monitored by growth in the size of the tailings, such as those in the vicinity of Globe, Arizona (upper right). Geologic structure, landforms, and urban development

Landsat image 1211-17334, February 19, 1973.

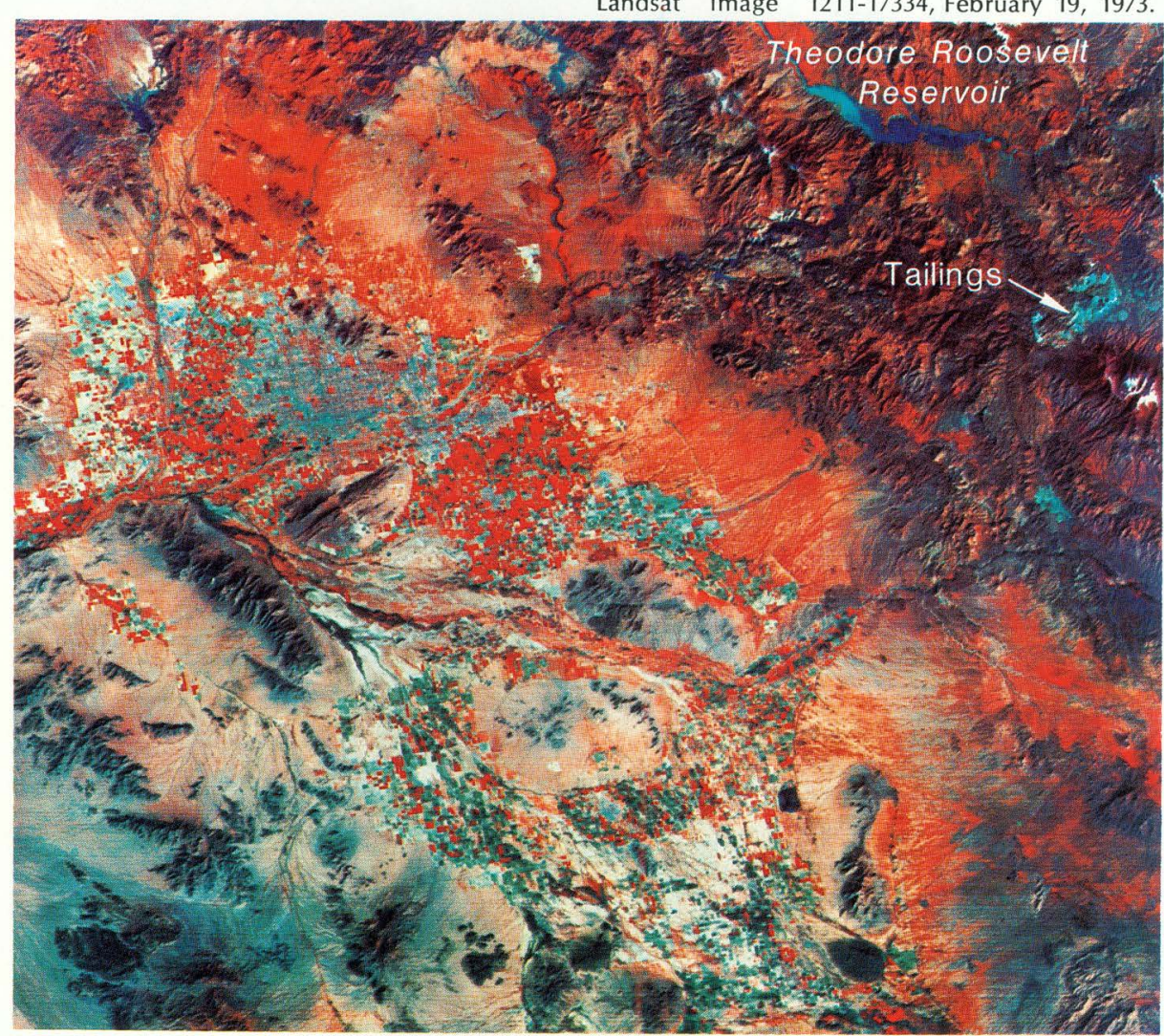




\section{Cartographic Applications}

Maps are basic tools for studying resources. They are essential in planning engineering works, geologic and hydrologic research, mineral investigations, flood control, soil conservation, reforestation, and land management. In short, maps depict the face of the Earth-its terrain, bodies of water, vegetation, and the works of man, all in measurable form and referenced to the figure of the Earth.

Satellites such as the Landsats offer several unique advantages to the mapmaker because their imagery has the following characteristics:

- Large areas shown in each image (185 x $185 \mathrm{~km}$ for Landsat).

- Multispectral views extending through the visible and most of the solar infrared wavelengths.

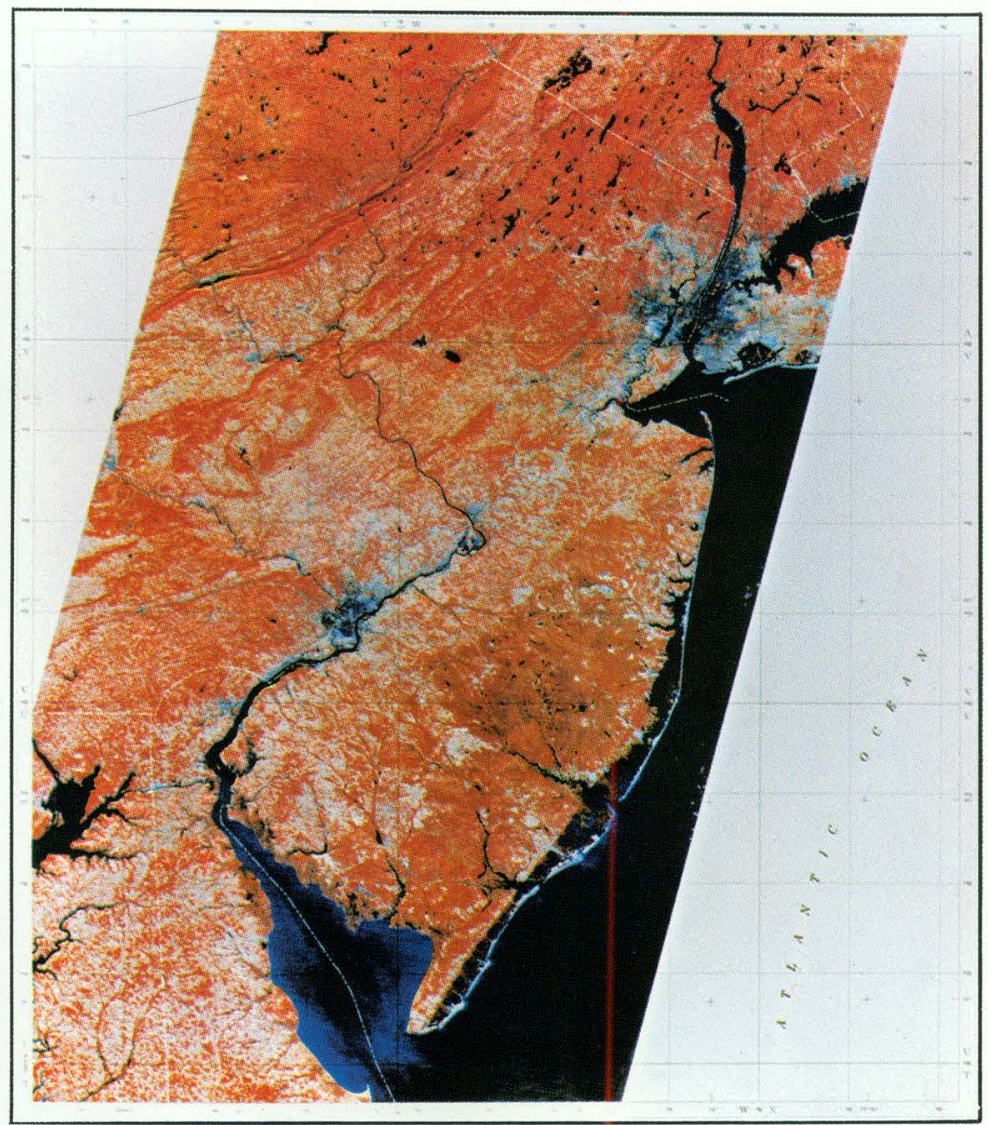

- Uniform aspect and Sun angle over each scene.

- Orthogonal (near-vertical) views of high geometric fidelity.

- Repetitive coverage based on an 18-day cycle.

- Image quality (resolution) adequate to delineate many major features commonly represented on medium- and small-scale maps and to indicate areas where large-scale map revision is needed.

- Potential for near real-time acquisition of data in a form suitable for automated map production.

Skylab's principal contribution to cartography is in demonstrating the use of photography taken of limited areas of the world, having a higher resolution that shows more detail than Landsat imagery. This photography is applied to various cartographic products and will assist in the design of future Earth-imaging systems.

At present, vast areas of the world are without meaningful map coverage, and certain remote areas, such as Antarctica, are largely unsurveyed. Image data obtained from orbiting satellites can greatly increase the efficiency of and reduce the time required for many planimetric mapping operations. Moreover, for the first time, the potential for mapping timevariant phenomena exists because of Landsat.

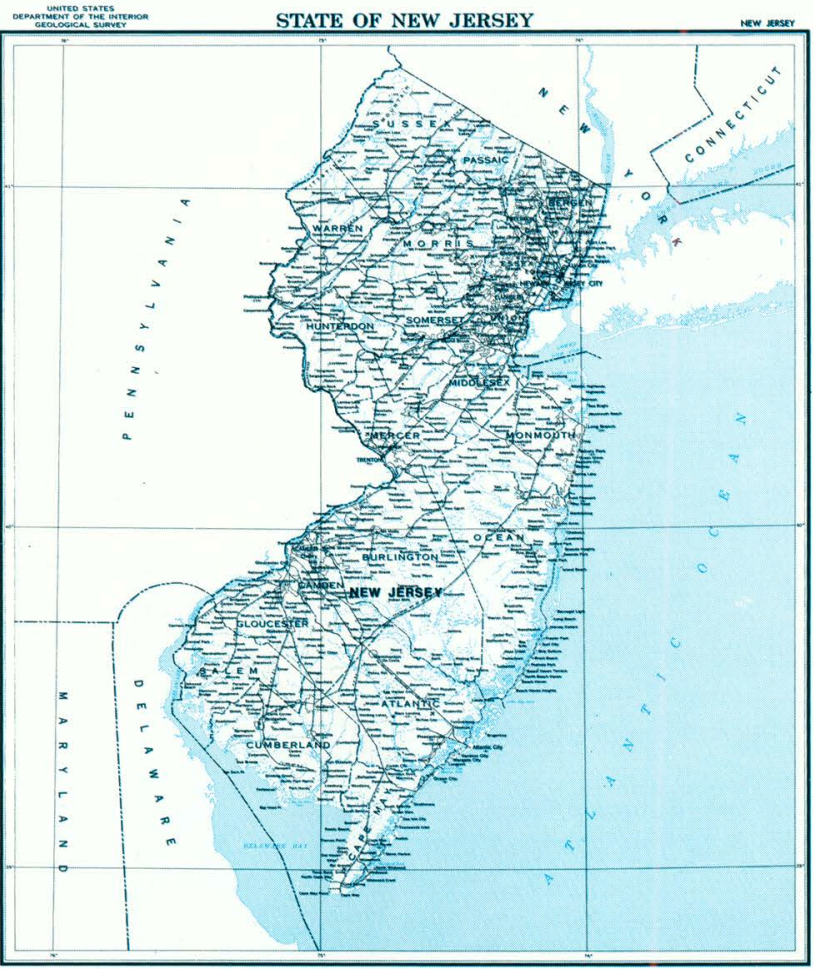

The satellite image mosaic of New Jersey, prepared from three consecutive Landsat images recorded on October 10, 1972, is comparable to the 1:500,000scale standard base map of the State. Images such as these form completely obinvalua invaluable as historical documents. Landsat image 1079-15133, October 10, 1972 


\section{Geologic \\ Applications}

The study of natural resources, and the appraisal of the probability of natural disasters, such as landslides, earthquakes, volcanic eruptions, and their possible effects on man, are major concerns of the U.S. Department of the Interior, and the Geological Survey.

Building on more than 25 years of experience in photogeology, Survey analysts are using satellite images and photographs to learn the regional significance of geologic structures, to help in the identification of areas favorable for the occurrence of mineral deposits, and to classify the vast dune fields of the world. Data relayed from ground sensors, via satellites, are being used to monitor changes in the frequency of occurrence of micro-earthquakes, tilt, and thermal activity associated with potentially active volcanoes.

An important attribute of space imagery is the way its small scale provides large-area coverage that emphasizes regional structure. There is an apparent relationship between scaie and magnitude of the structure that is easily recognized. For example, although regional structures are visible on a 1:1,000,000-scale (1 inch equals 16 miles) Landsat image mosaic of the United States, some structures of continental significance are more readily visible when viewed on the same mosaic reduced to a scale of $1: 5,000,000$ (1 inch equals 80 miles). By using Landsat images singly or compiled into mosaics, it has been possible to extend known geologic lineaments and recognize new ones. Because some mineral deposits are commonly concentrated at the junctions of major geologic lineaments, it has been possible to identify potential areas for mineral exploration.

Identification of rock types by using color photographs has been unsuccessful because surface color is an unsatisfactory indicator of rock composition. A technique is being developed, however, for using multispectral images from satellites to discriminate rocks containing iron. The technique involves the determination of the ratio of reflected visible light to reflected infrared radiation to discriminate subtle differences in rock composition. It has been applied experimentally for targeting potential mineral areas. The target areas' characteristics correlate well with sites of mines and prospects in the immediate areas.

The Geological Survey has emplaced seismic event counters and tiltmeters on 15 potentially active volcanoes in North and Central America. These gages measure two indicators of possible changes in volcanic activity. They are unique in volcano monitoring because they use the radio relay systems aboard the Landsat satellites to transmit measurements in near real time. Because the ground sensors are capable of unattended operation for more than a year, it is possible to efficiently monitor many volcanoes in areas geographically scattered from a central facility. The first preeruption activity transmitted through this network was the greatly increased number of seismic events beginning 9 days before the eruption that occurred at Fuego Volcano in Guatemala in 1973

Landsat imagery is used to identify targets for oil exploration. In this case, a large circular feature, several smaller circular features and lineaments have been recognized in the Gulf Coast region where many wells tap oil and gas adjacent to salt domes. Note the similarity between the known salt domes and the small previously unrecognized features. Landsat image 101516013, August 7, 1972.

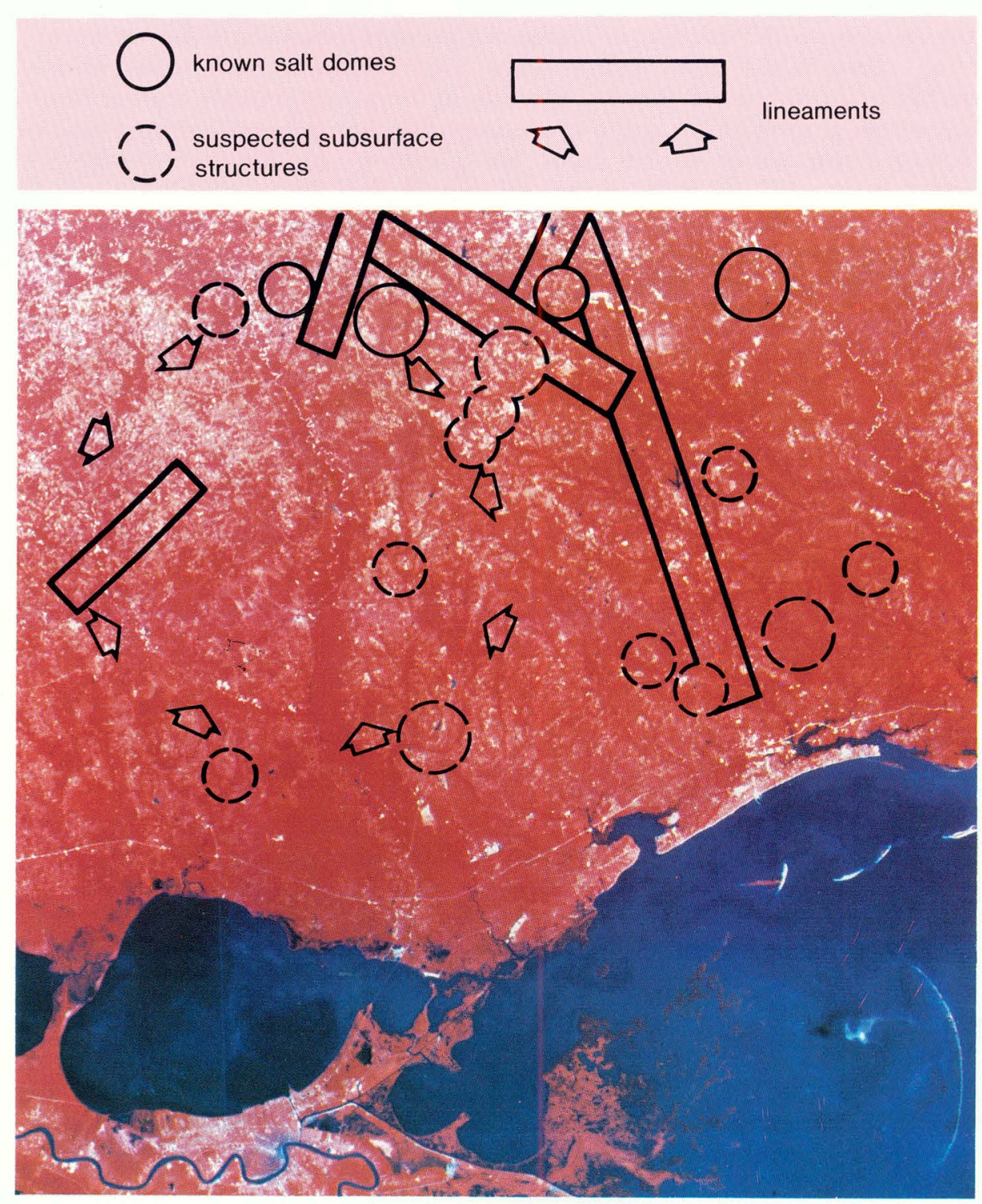




\section{Geographic \\ Applications}

Fundamentally, geography deals with location and arrangement of such factors as environmental conditions, Earth features, resources, population, and a wide range of other natural and cultural phenomena in relation to human activities. When the objective is to determine changes in human use of the Earth over large areas, data obtained from space are often more useful than larger scale data obtained from conventional aircraft or from ground surveys. Satellite observations provide a great reservoir of geographic information in a complete environmental context: singlepicture coverage of broad areas for planning; repetitive coverage for

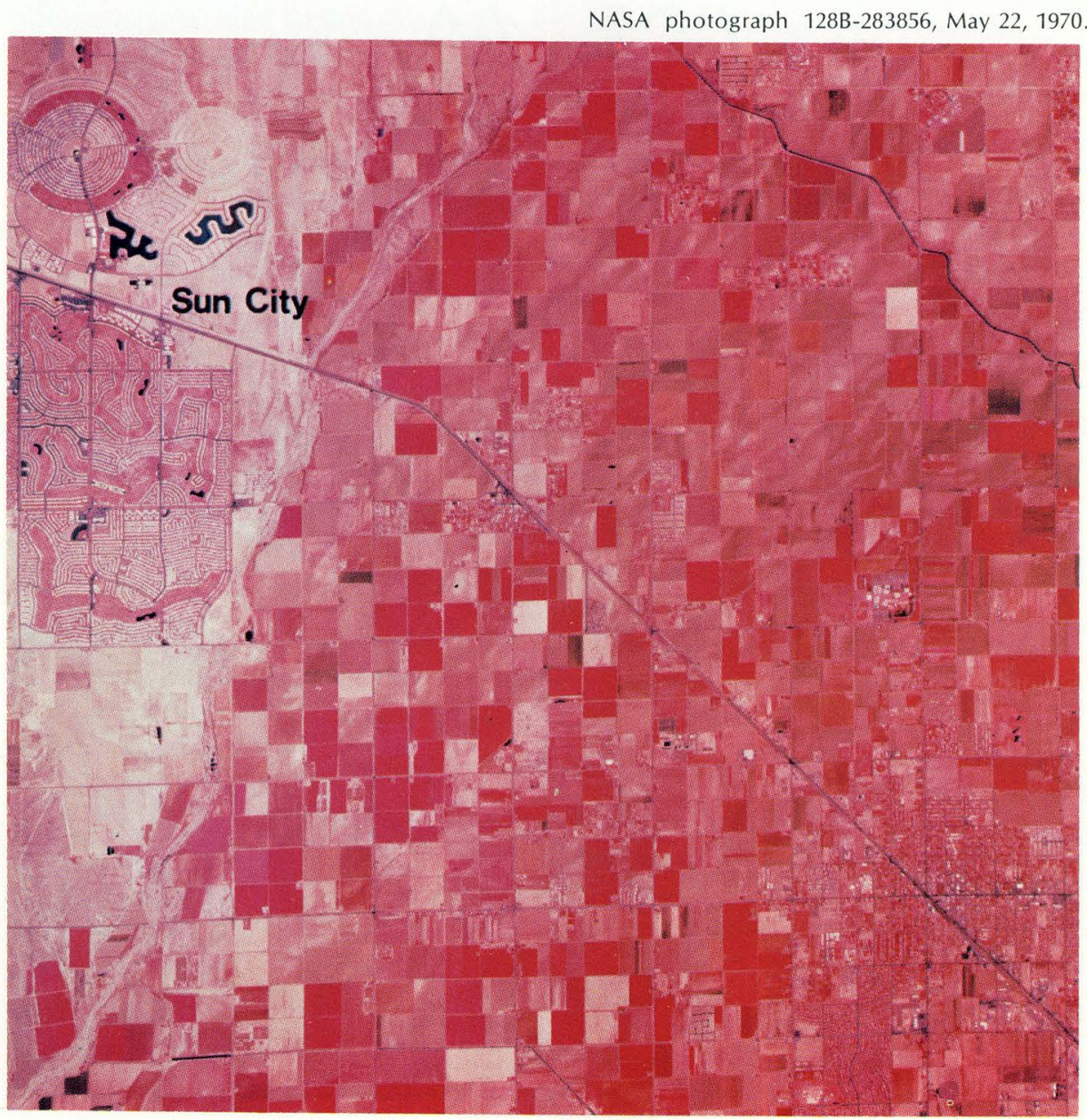

analyzing urban growth, functional changes, crops, and transportation linkages; emergency coverage for assessing effects of disasters; and scientific data for research and educational purposes. Space-acquired data can also be up to date, and at small scales, similar to those traditionally used for special-subject maps and for analysis of weather conditions, land use, and census results.

Land-use studies form the basis for regional planning. A demonstration study, for example, is being concluded in the Central Atlantic region of the United States using a variety of remotely sensed data, each of which makes a unique contribution to a comprehensive analysis of land use High-altitude aircraft data acquired in 1970 and supplemented by data from traditional sources are being correlated with satellite images acquired

Changes that occurred in the Sun City, Arizona area, between the time of the high-altitude Changes that occurred in the Sun City, Arizona area, between the time of the high-altitude
color-infrared photograph taken in 1970 and the Skylab-3 color photograph taken in 1973, are color-infrared photograph taken in 1970 and the Skylab-3 color photo
easily recognized by comparison of the distinctly circular pattern

Skylab-3 photograph S190B-86011, September 6, 1973

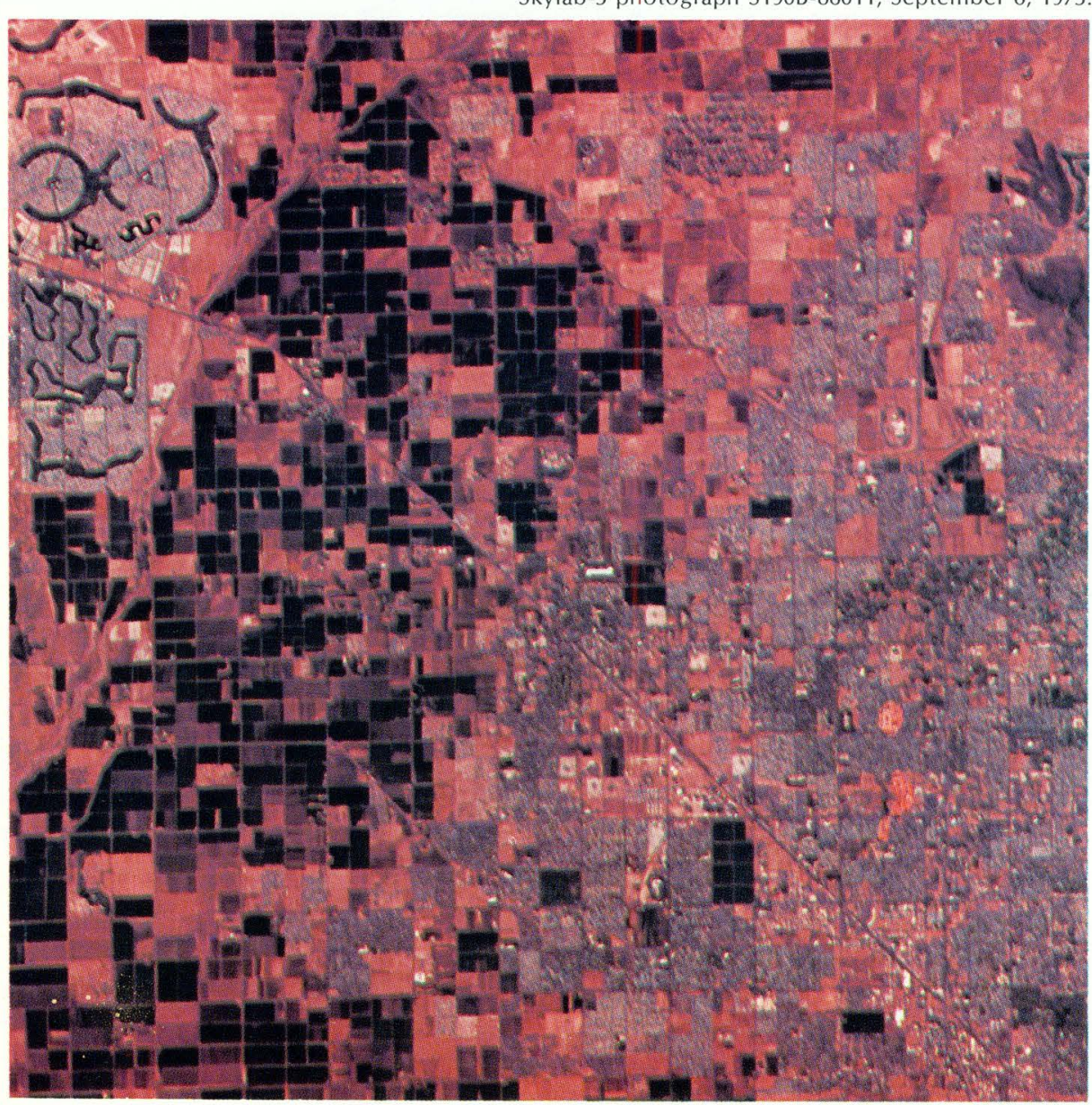


in 1972 and later to provide maps and computerized data banks that relate environmental conditions, human activities, and trends in land-use changes. The information can then be used as a basis for land-use policy decisions.

Urban change in selected cities is being detected by analyzing multispectral aerial photographs taken at the time of the 1970 census and in 1972. More recent data are provided by multispectral satellite imagery. The various wavelength bands are used singly and in combination to map several categories of land use. The verified, earlier data are the basis for computer recognition of features in the satellite images for automatic mapping of urban change and portrayal at scales as large at 1:24,000 (1 inch equals 2,000 feet).

Regional planning and urban change detection studies have validated the levels of detail in a proposed national land-use classification system developed to take advantage of remotely sensed data acquired at various altitudes in the most cost-effective manner.

Changes in the Phoenix, Arizona area, between November 1970 and May 1973 detected from Landsat data are superimposed as dark patterns on a 1970 land-use map. Red is new residential areas; dark blue is new water areas; and dark green is new cropland.

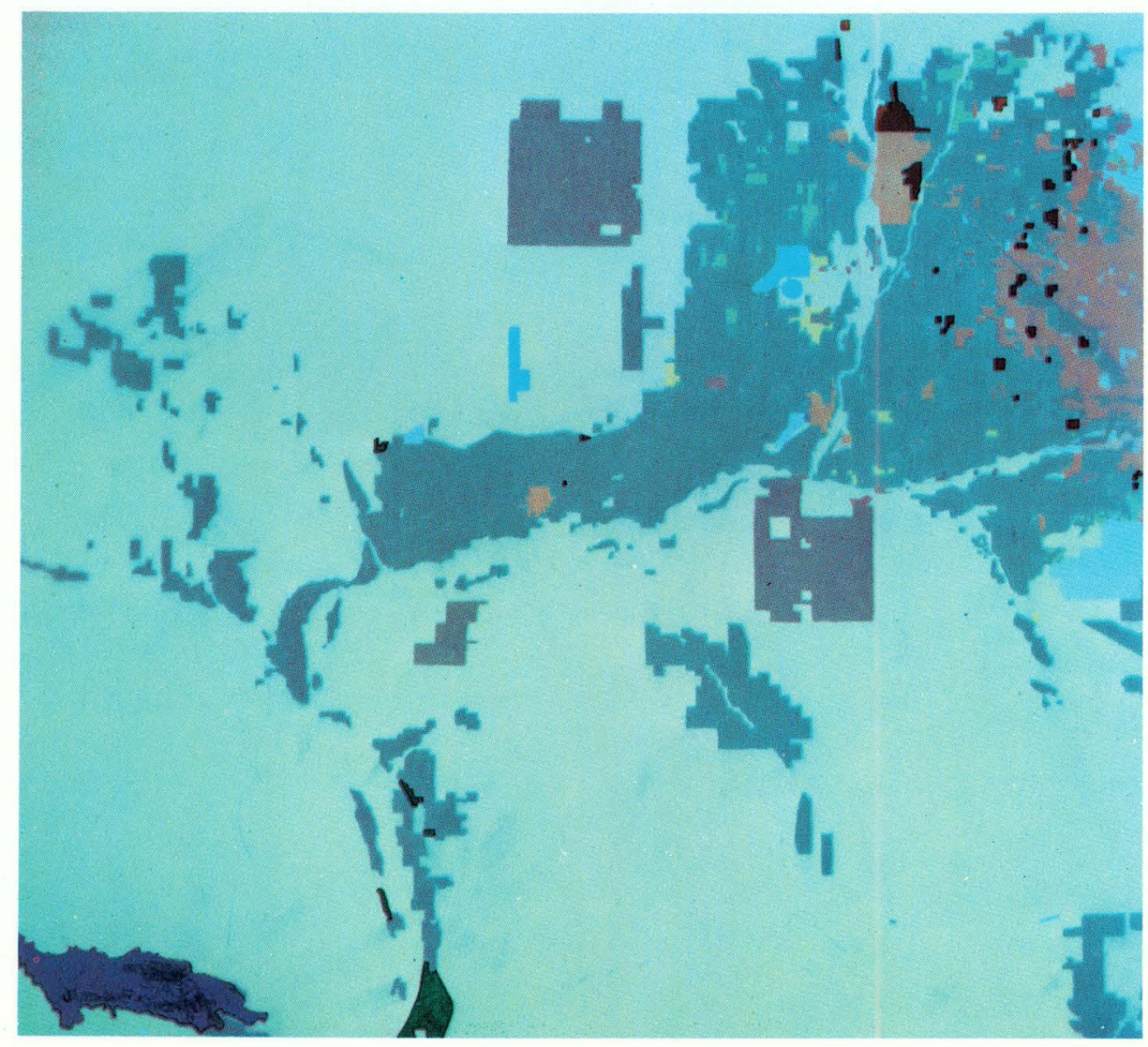

Five basic dune forms have been recognized from Landsat imagery (shown from top to bottom) parallel straight or linear; parallel wavy or crescentic; star or radial; parabolic or U-shaped; and sheets or stringers.
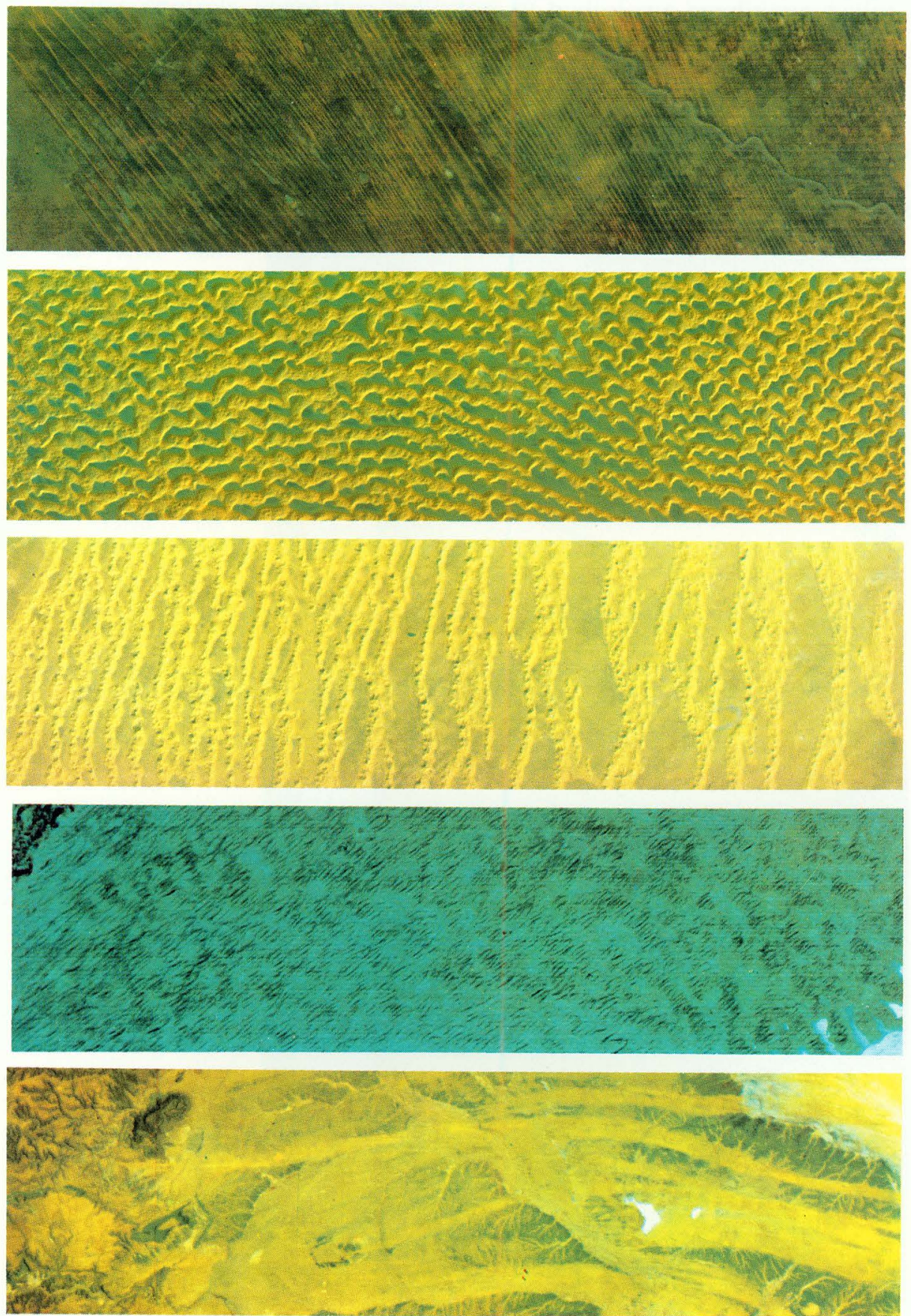


\section{Hydrologic \\ Applications}

Important water resources planning and management information is obtained from Earth-orbiting satellites. The perspective from space adds an areal dimension to conventional hydrologic data collected at point stations. Approximately 10,000 continuous water-stage recorders on streams,

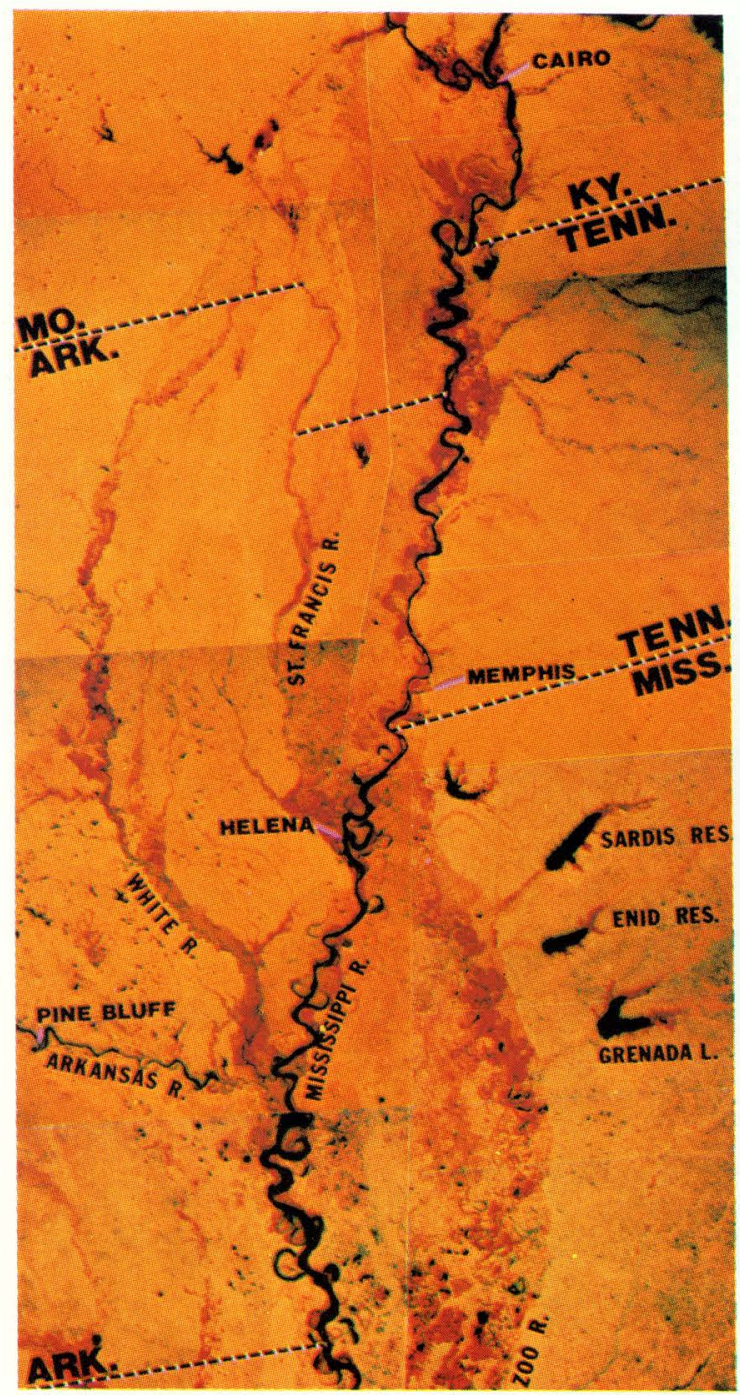

plus several times that number of ground-water wells and water-quality monitors are operated in the United States by the Geological Survey. A small number of the stations use the Landsat Data Collection System to transmit the data. Synoptic information on drainage-basin characteristics, hydrologic controls, vegetative indicators of hydrologic conditions, hydrodynamics, lake processes, pollution dynamics, and hydrometeorological variables such as distribution of snow and ice can be obtained from satellite images and can often be used to extend the continuous station records over large areas adjacent to the measured drainage basin.

Discharge from Lakes Michigan, Superior, and Huron is through the St. Clair River into through the Detroit River into Lake Erie. A few days before this image was recorded, areas to the north were subject to flooding which increased the sediment load in the drainage system. The added sediment accentuated the turbidity patterns created by the wind and river currents. dies especially the eddies along the eastern and the distribution of sediment from the Detroit River and Maumee River. Landsat images 1247-154815, March 27 1973, and 1247-154745 March 27, 1973. Band 5.

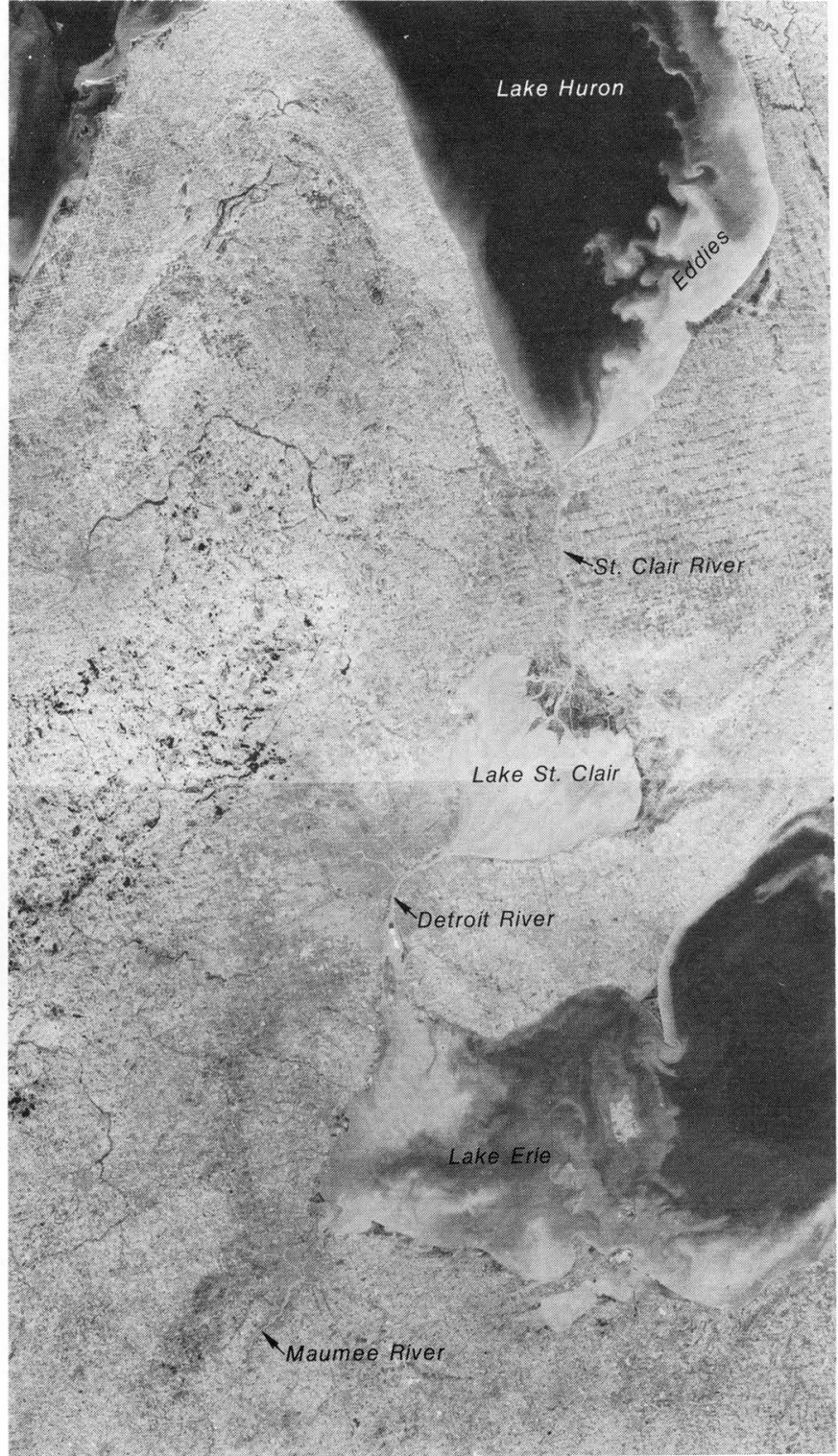


Hydrologic data collected at some stations by ground sensors and experimental transmitters are relayed via satellite. This system has the advantage of timeliness of data, infrequency of maintenance, and easy recognition of equipment failure. Within the Everglades, for example, 13 ground platforms in remote areas provide twice daily water-level and cumulative rainfall data which have been used to devise a simplified water budget for one of the local management areas. In Arizona, the near real-time stream flow data acquired from platforms on the Salt, Verde, and Gila Rivers played a role in the regulation of storage reservoirs to minimize spring flooding in the Phoenix area in 1973. In the Delaware River basin, such platforms are part of the established hydrologic data network. They transmit data from six water-quality monitors, eight stream gages, and three ground-water observation wells that contribute to the information system used for riverbasin management.

The ability to map snow cover from satellite imagery also has practical importance. The measurement of variation in mountain snowpack provides data on expected spring or summer streamflow needed for the efficient regulation of hydroelectric, flood control, or irrigation reservoirs. Using the concept of an equivalent snowline altitude, above which the area of a basin or mountain is equal to the area of snow cover, it is possible to determine from satellite images the snow cover area and changes which permit measurement of the snowpack and estimation of the spring runoff in near real time.

Water quality (based on the concentration of sediment and chemical and biological constituents in water) is commonly measured by sampling procedures or by continuously recording monitors. Multispectral images from aircraft and satellites enhance many of the contrasts on the surface of water bodies and permit the detection and mapping of floating algae, foam, and other materials, as well as sediment patterns. Sewage and industrial waste outfalls also have been identified where there was a significantly different reflectance from that of surrounding water. When images or photographs are taken repetitively, it is possible to study the

Comparison of a Landsat image of Mountain Meadows Reservoir, California, recorded on July 25, 1972, and enlarged to 1:250,000 scale, with one from August 13, 1972, shows that the area of the reservoir has decreased by about half in 18 days. Natural conditions, such as this, can be measured and modeled from repetitive satellite data to derive resources management information. Landsat images 1002-18125, July 25, 1972, and 1020-18103, August 13, 1972.
Landsat Data Collection Platform to relay water-level data.

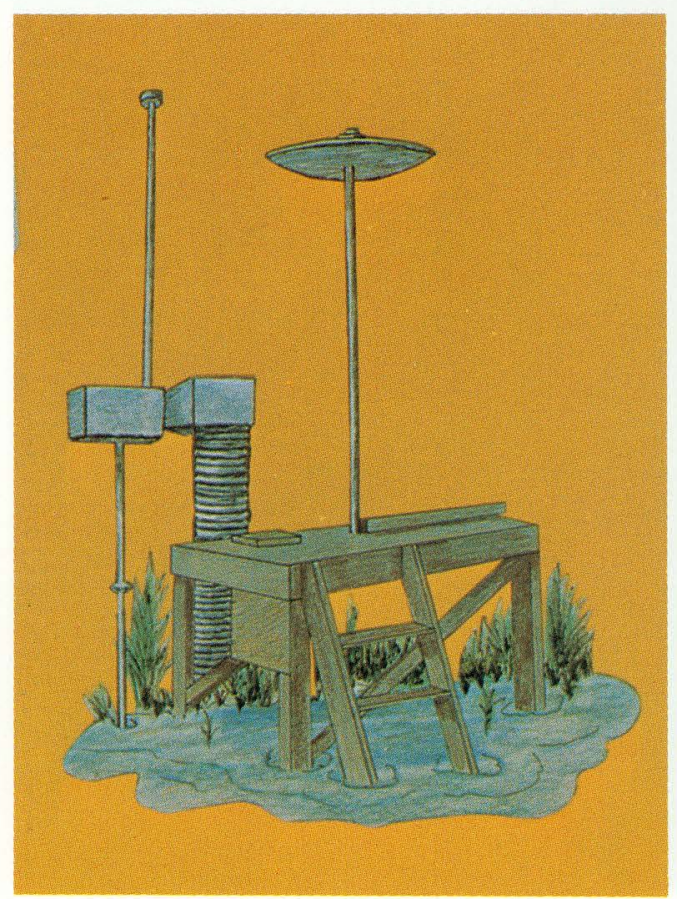

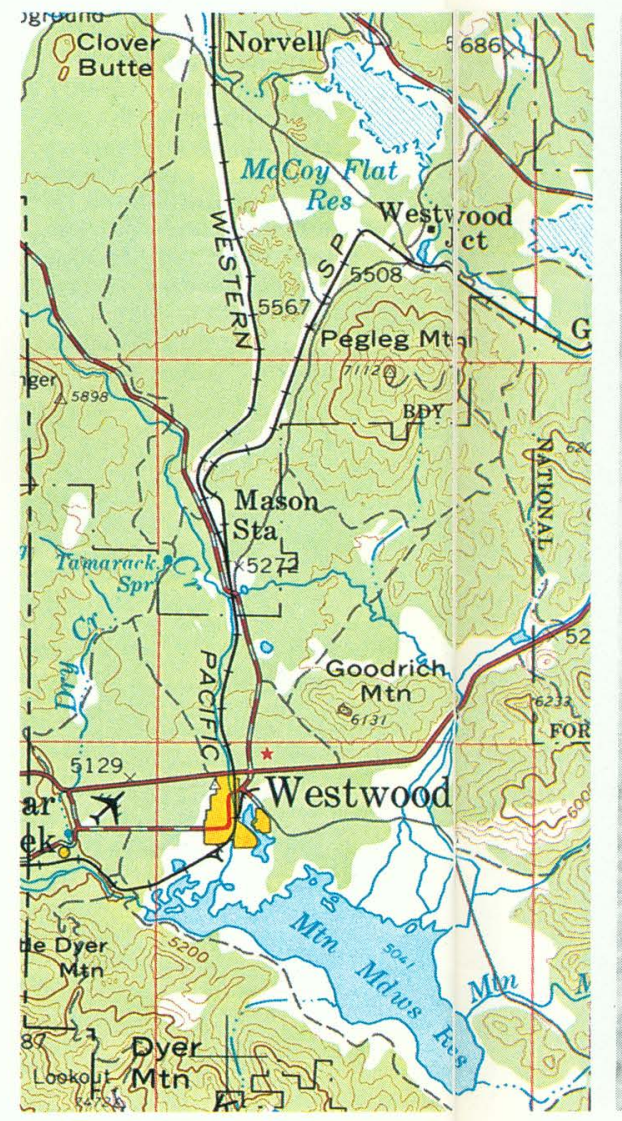

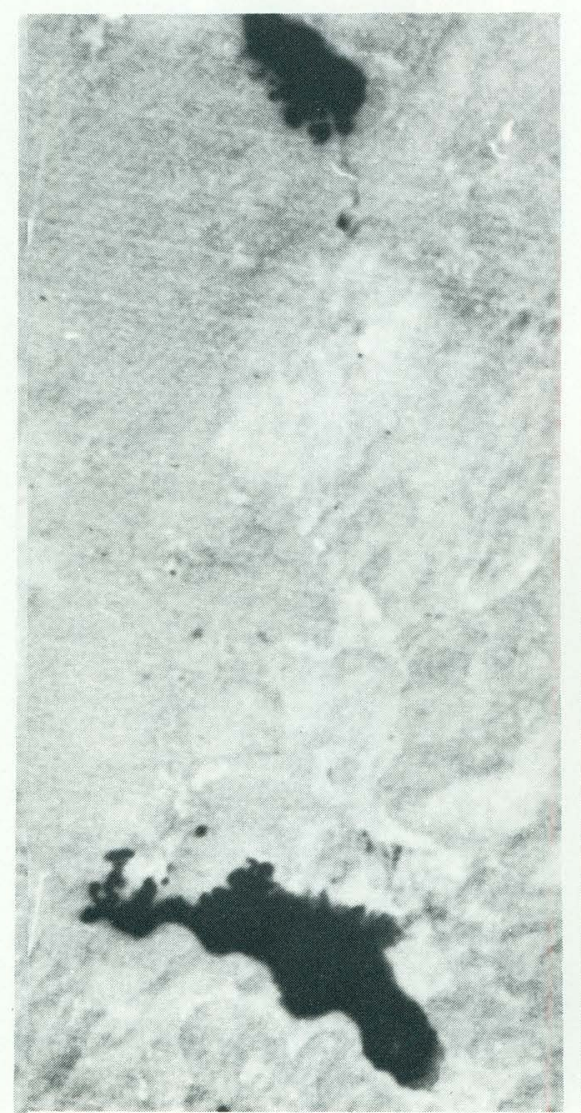

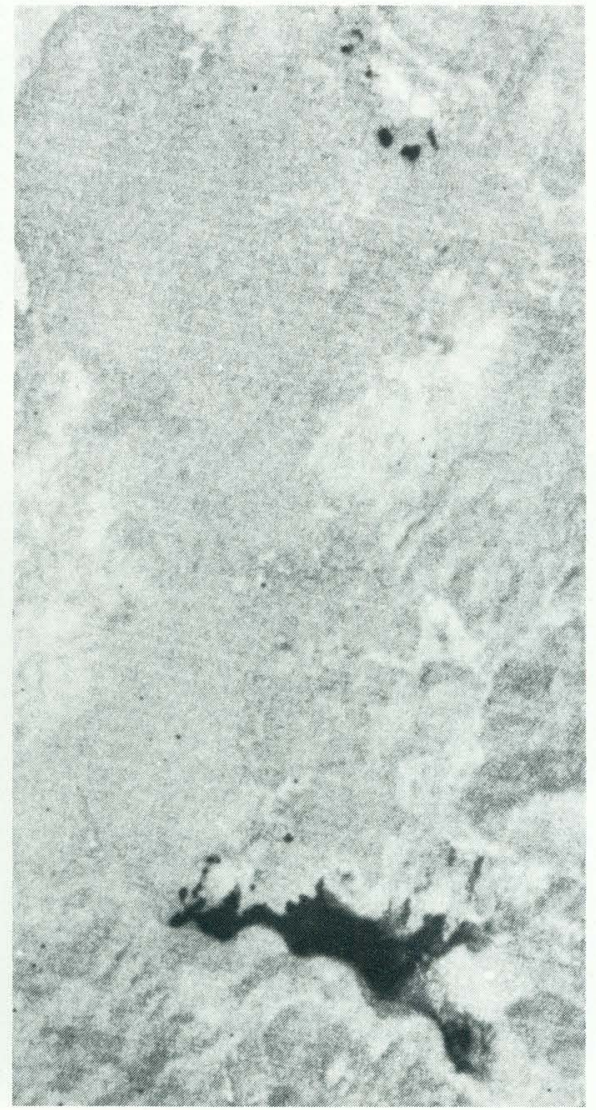


dynamics of pollution - the rate at which pollutants move and the characteristics of dispersion. Direct measurement of the presence or concentration of dissolved constituents in water is not possible, at the present time, with remote-sensing technology.

By analyzing two wavelength bands of satellite multispectral imagery, including one in the near infrared which has the particular ability to distinguish living vegetation, it has been possible to monitor the growth and spread of phreatophytes (water-loving plants) in beds of intermittent streams and along watercourses in the Southwestern United States. These plants use much of the limited water supply, and their effective control is important in water-resources management and planning.

The wetlands along the southern coast of New Jersey appear as the maroon strip behind the dry coastal beaches dotted with characteristic light blue or gray of urban development from zone and many of the coastal States are using remotely rensed dan of ecology of the coastal this fragile marine marsh environment. Landsat image 1079-15133, October 10, 1972.

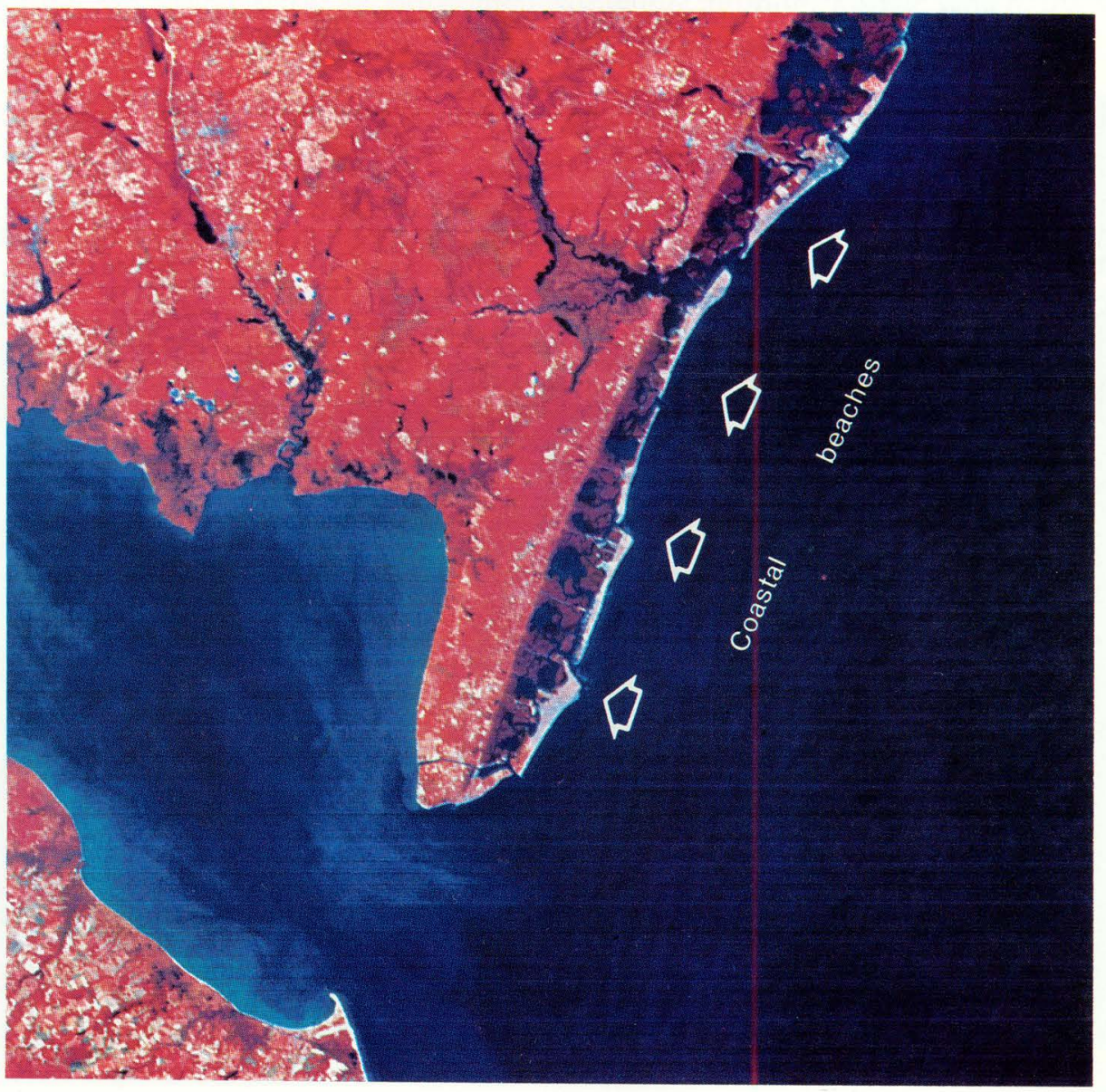

\section{Marine \\ Applications}

Approximately 70 percent of the Earth's surface is covered by water and much of it is not practically accessible for broad surveillance by conventional methods. Remote sensors, especially in spacecraft, offer new opportunities to learn about the oceans and their potential. The Department of the Interior's interest is concentrated in the near-shore environment. Investigations concern what is there and how it changes, including surface temperature, current patterns, types of waves, underwater topography, marine biology, mineralization, petroleum accumulation, and coastal processes. In pursuit of this knowledge, repetitive photographs can be used to provide information on direction and rate of movement and relative quantity of suspended matter. This information in turn can be used to predict changes in coastal morphology and current patterns.

A study of Cook Inlet, Alaska, illustrates several specific applications of satellite imagery. The inlet is important as a fishery is the site of oil production and potential spills, is a turbulent navigation channel to Anchorage, and receives vast quantities of sediment-laden glacial water. The circulation pattern of the inlet is poorly understood because of its vast size. The sediment-laden water is distinguishable from the relatively normal seawater on multispectral satellite images. The boundary between the sediment-laden and normal seawater is important because it is the location of concentrations of fish, is the site of higher waves, and is the "trash line" for flotsam that is a navigational hazard. Interpretation of the synoptic satellite images of the inlet and comparison of the repetitive coverage are making the circulation pattern clearer. Understanding of the pattern can improve navigation and fishing and protect the fishery from potential pollution.

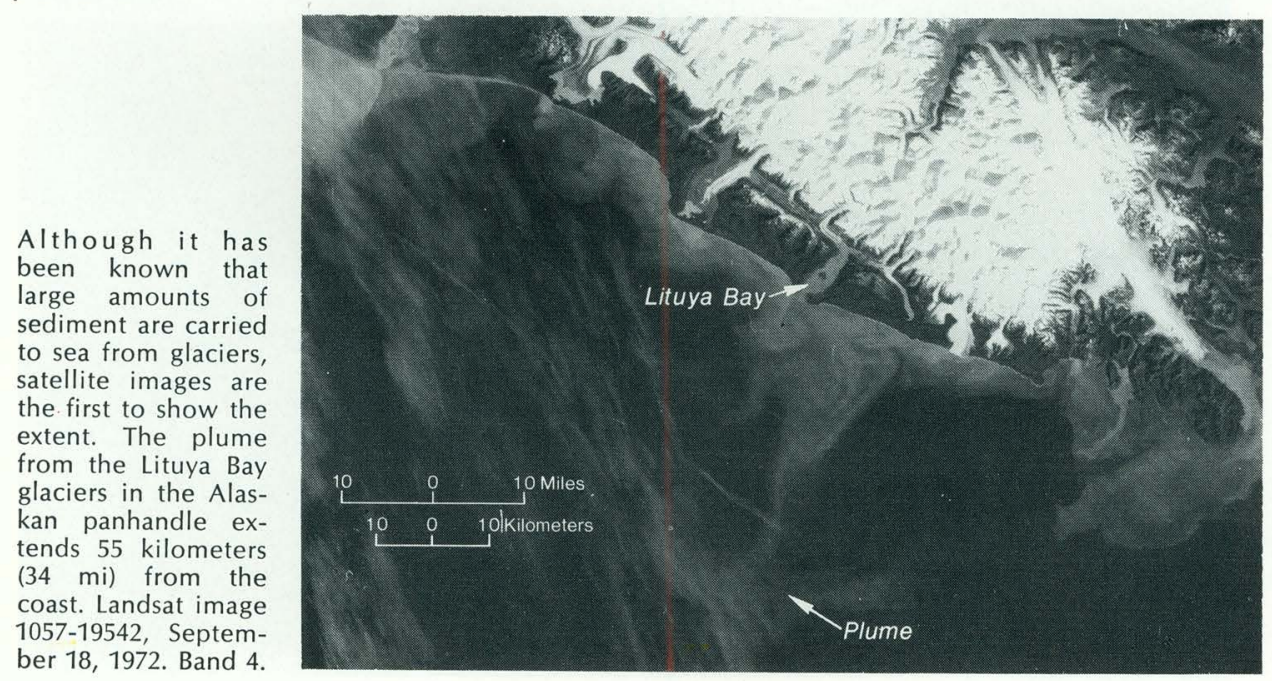




\section{Land Management Applicatıons}

Public lands, national parks, and national forests comprise 175 million acres primarily in the Western United States and 348 million acres in Alaska. Beyond their value as a future resource base, these public lands yield a substantial income to the Nation from oil, gas, forest products, grazing, and recreation fees. Moreover, about 7 million head of livestock and nearly 3 million big-game animals depend on these lands for all or part of their year-long needs.

Strip mining and subsequent reclamation are recognized subjects for periodic monitoring from space. It has been possible to measure the increase in area stripped in a year in parts of the Eastern United States and to evaluate the effectiveness of reclamation efforts. Revegetation of stripped lands can be monitored by using the infrared response to vigorous vegetation and the periodic satellite coverage.

Range conditions on public lands in the Western United States are also being checked and predicted using repetitive coverage by Landsat. These lands are leased on the basis of the capacity of the grasses to support or carry so many head of livestock per acre. It is the responsibility of local

The major feature on this Landsat image taken over northern Alaska is a large forest fire on the right. The burned area is black, surrounded by the iiving vegetation in red. A number of smoke plumes originate at edges of the burn and trail slightly southwest into the Zane Hills. An olde burn, to the left, was a lightning-caused fire that burned 56,000 acres of public land in the status of veretation in this area. Landsat image 1003-21355, July 26, 1972.

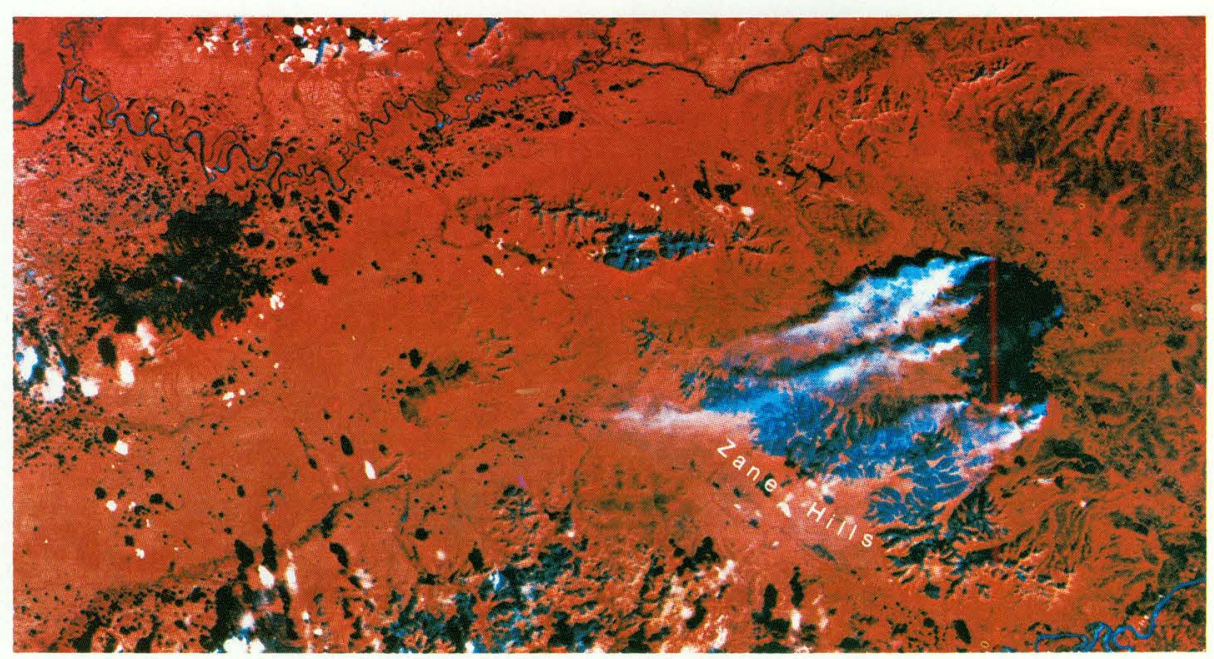

range managers to prevent overgrazing and yet maintain maximum use. Space data could give them near real-time information with which to make decisions.

The regional overview of physiographic relationships provided by a Landsat image of the Chaco Canyon area of New Mexico suggested the explanation for the extensive prehistoric road network created by Pueblo Indians, who had no knowledge of the wheel. Archaeologists of the National Park Service mapped about 200 miles of these roadways using black-andwhite, color, and color-infrared aerial imagery, and estimated that an additional 200 miles existed. Plotting the road system on the Landsat image showed that the major branches led to potential resource areas: timbered mountains for wood and hunting river areas for fishing and source areas for pottery clay. Thus, the roads not only integrated the communities of the area, but also provided access to resources outside their sphere of occupation and influence. Existing data recovered through excavations in Chaco Canyon support this explanation.

This image of south Florida delineates surface water patterns and water distribution within the Everglades and Big Cypress Swamp for determining better management practices for these two areas. The pink tear-shaped areas within the Everglades are tree islands, and the darker tones are standing water. Repetitive images from the Landsat provide the information to recognize the effect of water management for agricultural purposes in the northeast, and the effect of urban encroachment from the east and west on the ecological system of the Everglades. Landsat image

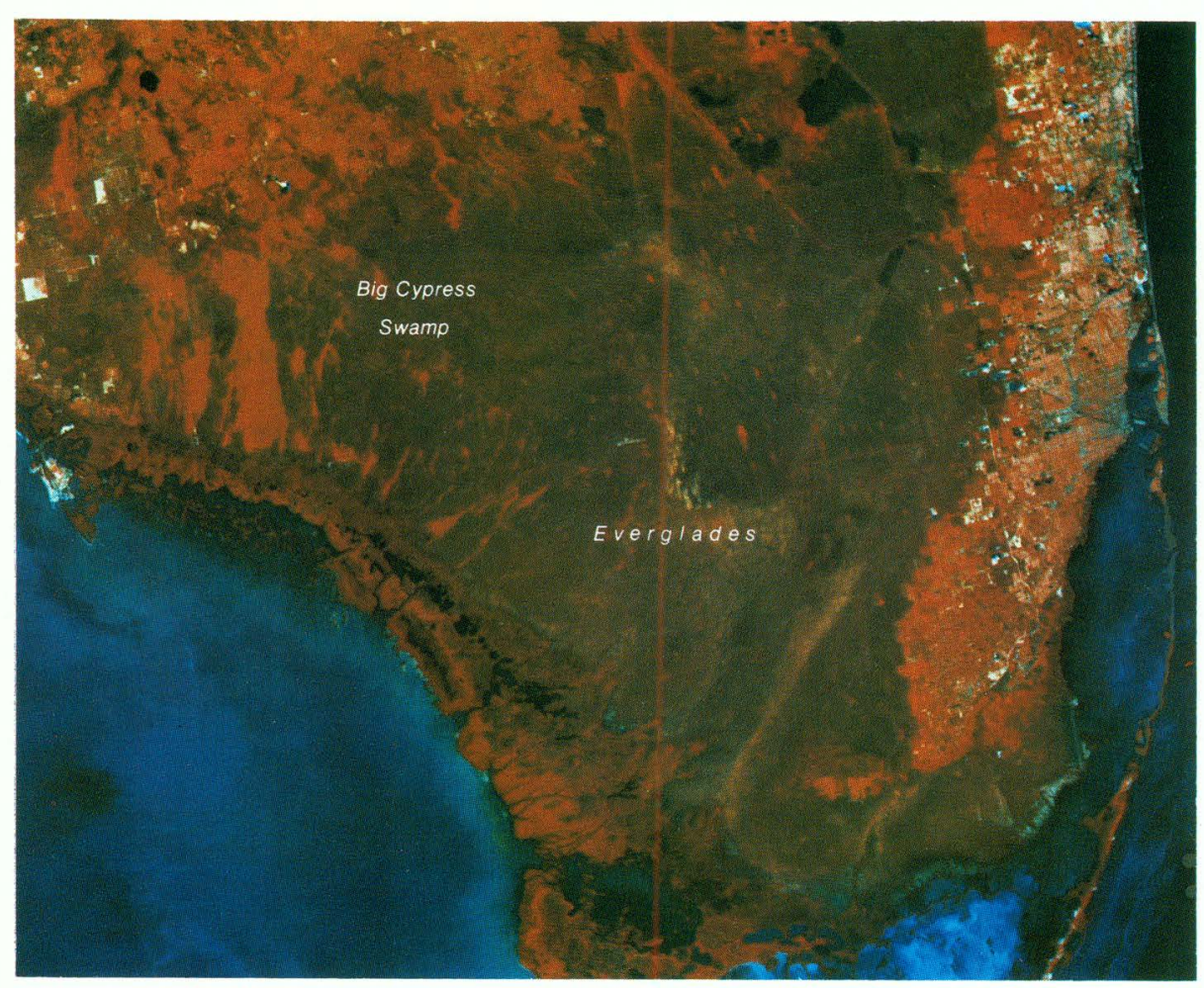




\section{Response to the Resource Challenge}

Don Kulow Librany

EROS Data Center

Sioux Falls, SD 57198

On the basis of the potential of remote-sensing technology, and in response to the critical need for greater knowledge of the Earth and its resources, the Department of the Interior, in 1966, established the EROS (Earth Resources Observation Systems) Program to gather and use remotely sensed data of natural and man-made features of the Earth's surface collected by satellite and aircraft. The EROS Program supports the development of operational uses of the data in Departmental activities. The purpose is to make maximum use of remote-sensing technology, including data from satellites, aircraft, and automatic information extraction for real-time management decisions.

The EROS Program is managed by the U.S. Geological Survey. Other agencies of the Department of the Interior that utilize the data and technology from the EROS Program include: Alaska Power Administration Bonneville Power Administration, Bureau of Indian Affairs, Bureau of Land Management, Bureau of Mines, Bureau of Outdoor Recreation, Bureau of Reclamation, Fish and Wildlife Service, National Park Service, Office of Water Research and Technology, Office of Territorial Affairs, Southeastern Power Administration, and Southwestern Power Administration.

The EROS Program and the use of remote sensing from spacecraft and aircraft enable the Department of the Interior to apply (1) the improved capability to study and inventory natural resources from data obtained from remote-sensing devices and (2) the broad regional coverage and frequent repetitive coverage provided by Earth-orbiting satellites to the development of more effective resource information systems.

The EROS Data Center was established as a facility of the EROS Program to reproduce aerial and space remotely sensed data and to make them available to anyone. The Data Center sells images, photographs, and electronic data originally acquired by 16 different agencies and reproduced in more than 20 different formats. Assistance is available at the Center in manipulation and interpretation of the data. This is augmented by periodic training courses. For information on Landsat and other remotely sensed data or training, write to EROS Data Center, Sioux Falls, South Dakota 57198.

\begin{tabular}{|ll|}
\hline & Space-A cquired Earth Resources Data \\
Gemini & Color photographs of random land and sea areas between about \\
Apollo & $30^{\circ} \mathrm{N}$ and $30^{\circ} \mathrm{S}$ latitude. \\
Color photographs of random land and sea areas, and multi- & $\begin{array}{l}\text { Spectral photographs of Southern U.S. from Apollo 9. } \\
\text { Landsat }\end{array}$ \\
Skylab & $\begin{array}{l}\text { Multispectral repetitive images of most of the land areas of the } \\
\text { Eultispectral photographs, color and black-and-white photo- } \\
\text { graphs, and multispectral images of scattered areas throughout } \\
\text { the world. }\end{array}$
\end{tabular}

is U.S. GOVERNMENT PRINTING OFFICE : 1977 O-236-460

\section{QB 637 . G46 1977 \\ Geological survey (U.S.) \\ Studying the earth from}

space

\section{Photo Credit}

Photographs of Copiah County, Mississippi and Sun City, ArizonaEarth Resources Laboratory, National Aeronautics and Space Administration. 
As the Nation's principal conservation agency, the Department of the Interior has responsibility for most of our nationally owned public lands and natural resources. This includes fostering the wisest use of our land and water resources, protecting our fish and wildlife, preserv. ing the environmental and cultural values of our national parks and historical places, and providing for the enjoyment of life through outdoor recreation. The Department assesses our energy and mineral resources and works to assure that their development is in the best interests of all our people. The Department also has a major responsibility for American Indian reservation communities and for people who ive in Island Territories under U.S. administration.

Cecil D. Andrus, Secretary

U. S. Department of the Interior

V. E. McKelvey, Director Geological Survey

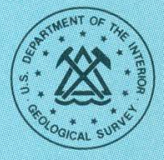

